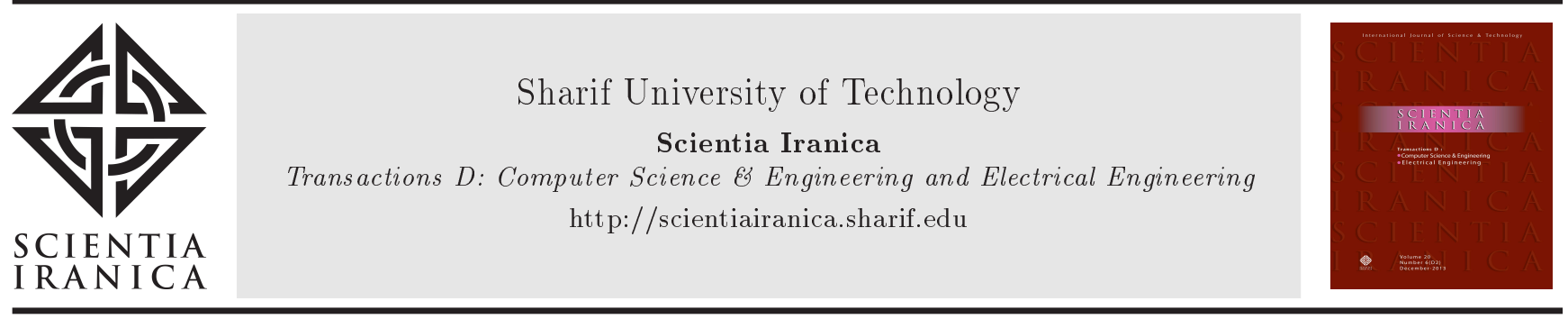

Research Note

\title{
Sensitivity analysis of economic variables using neuro-fuzzy approach
}

\author{
E. Lotfi ${ }^{\mathrm{a}, *}$, S. Babrzadeh ${ }^{\mathrm{b}}$, and A. Khosravi ${ }^{\mathrm{c}}$ \\ a. Department of Computer Engineering, Torbat-e Jam Branch, Islamic Azad University, Torbat-e Jam, Iran. \\ b. Department of Computer Engineering and Information Technology, Payam-e Noor University, Asalooye, Iran. \\ c. Center for Intelligence Systems Research, Deakin University, Geelong 3217, Australia.
}

Received 31 October 2017; received in revised form 17 February 2019; accepted 4 May 2019

\section{KEYWORDS}

Fuzzy forecast;

Economic time series;

Sensitivity analysis;

Soft computing;

Economic

management.

\begin{abstract}
Sensitivity Analysis (SA) is an essential requirement for decision-making in economic management. In this paper, a novel Fuzzy Sensitivity Analyzer (FSA) is proposed to analyze the sensitivity of economic variables. The proposed FSA algorithm consists of an Adaptive Neuro-Fuzzy Inference System (ANFIS) that is adjusted for forecasting economic time series. Based on the output of ANFIS, FSA can determine the importance degree of parameters. In the numerical studies, the proposed method is applied to carry out the sensitivity analysis of oil and gold time series. According to the results, FSA indicates that oil price is highly dependent upon the inflation rate, dollar index, and market index, while OPEC production level and gold price are of low impact. Furthermore, in the gold price modeling, the highest sensitivity is obtained from silver price, while demand for gold is a function of market index and inflation rate. The proposed method can be used in many SA applications.

(C) 2020 Sharif University of Technology. All rights reserved.
\end{abstract}

\section{Introduction}

An economic time series is a sequence of successive measurements of an economic activity obtained at regular time intervals (hourly, daily, weekly, monthly, quarterly, or annually). It can include price sequence of a commodity or a sequence of economic indexes, e.g., oil price, gold price, and market index. In this framework, researchers and economic analyzers consider a critical issue of the Sensitivity Analysis (SA) of variables and the determination of their importance [1]. SA determines the relationship between economic parameters and can help economic managers

*. Corresponding author.

E-mail address: esilotf@gmail.com and elotfi@bitools.ir (E. Lotfi)

doi: $10.24200 /$ sci.2019.5488.1305 with decision-making in economic problems. In the literature, there are two approaches for SA methods: local and global methods [2-6]. Local or one-factor-ata-time methods are limited to examining the effects of variations in input parameters in the vicinity of their nominal values. Global SA methods define the contribution of individual input parameters, including their sets, and provide more comprehensive information on the computational model regarding changes in input parameters throughout their domain $[2,4-8]$. Some mathematically based SA methods have been proposed in this regard. For example, Yazdani-Chamzini et al. [9] applied the Cosine Amplitude Method (CAM) to find the most sensitive parameters. Although CAM and other mathematically based SA methods applied in the referenced studies [10-14] can be used for economic time series [15], they cannot consider the behavioral similarities of parameters. They do not consider the interactions among the parameters [7]. Therefore, they 
cannot be a proper method in the case of economic variables. On the other hand, learning-based SA methods $[9,16]$ can learn the interactions among economic parameters and, consequently, can better assess the influence of parameters on the output of an economic model. For example, Valdivia and Arturo [16] applied an Artificial Neural Network (ANN) for SA. In contrast to mathematical methods, ANNs can learn the nonlinear behavior and, hence, show better results in SA. In a number of referenced studies [3,11,12,17], fuzzy-based Multiple Criteria Decision-Making (MCDM) models were reviewed, and the effectiveness of an SA with respect to the fuzzy MCDM systems was shown. This paper aims to propose a novel learning-based SA method using Adaptive Neuro-Fuzzy Inference System (ANFIS). ANFIS is successfully applied in various applications from prediction [18-23] to estimation [22$24]$ and features a large number of learning parameters compared with ANNs; it may show more accurate results [22]. To the best of our knowledge, fuzzy approaches have not yet been examined in the SA of economic variables; now, they are introduced in this study, and the resulting model will be applied to the SA problems of oil and gold price and demand [19-24]. The proposed method is generalizable and can be used in various applications [19-24] such as product cost estimation [21,25] and stock price prediction [26-28].

The paper is organized as follows. A short review of ANFIS is presented in Section 2. The Fuzzy SA (FSA) is proposed in Section 3. Then, it is evaluated in Section 4, and conclusions are drawn in Section 5.

\section{ANFIS}

The architecture of Sugeno-type ANFIS [32,33] presented in Figure 1 includes the following five layers: fuzzifier, production, normalized, defuzzification, and output layer. Through these layers, the output of ANFIS is determined. Figure 1 shows a two-input single-output architecture as an example. Figure 2 shows its inference mechanism. This example includes two linguistic rules as follows:

Rule1: If ( $x$ is $A_{1}$ ) and ( $y$ is $\left.B_{1}\right)$,

$$
\text { then } z_{1}=p_{1} x+q_{1} y+r_{1}
$$

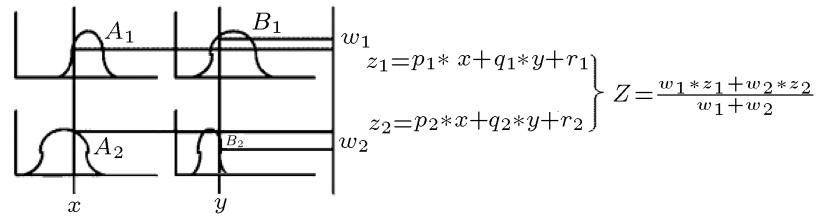

Figure 2. Fuzzy reasoning of Adaptive Neuro-Fuzzy Inference System (ANFIS) presented in Figure 1 [32-35].

Rule 2: If ( $x$ is $A_{2}$ ) and ( $y$ is $\left.B_{2}\right)$,

$$
\text { then } z_{2}=p_{2} x+q_{2} y+r_{2}
$$

where $p_{1}, p_{2}, q_{1}, q_{2}, r_{1}$, and $r_{2}$, are linear parameters, whereas $A_{1}, A_{2}, B_{1}$, and $B_{2}$ are nonlinear and called membership functions. The final output of ANFIS is formed through Eq. (1):

$$
Z=\frac{w_{1} z_{1}+w_{2} z_{2}}{w_{1}+w_{2}}
$$

In this sample, ANFIS architecture of the learning parameters including $p_{1}, p_{2}, q_{1}, q_{2}, r_{1}, r_{2}$, and $A_{1}$, $A_{2}, B_{1}, B_{2}$ should be adjusted. This adjustment is done by using input-target examples, error backpropagation, and LMSE algorithm. In Sugeno model, the subtractive clustering method can be applied [31-35]. More descriptions can be found in [29,30-34,36,37].

In this section, a novel method based on ANFIS is proposed to identify the most sensitive factors affecting price and demand.

In contrast to mathematical methods, the proposed method, namely Fuzzy SA (FSA), considers the behavioral similarity of variables. FSA is based on the behavior learning and can extract the most affecting independent parameters from input variables.

Let $\mathrm{EV}$ be a set of economic parameters under consideration (Tables 1 and 2).

$$
E V_{i}=\left\{\operatorname{Inf}_{i}, \operatorname{Int}_{i}, \mathrm{Opl}_{i}, \mathrm{Gol}_{i}, \operatorname{Sil}_{i}, \operatorname{Dji}_{i}, \operatorname{Din}_{i}\right\},
$$

where $i$ is the index of sample number. If a variable such as Int is removed from $E V$, then we have a new set like $E V_{-I n t, i}$, which is as follows:

$$
E V_{-I n t, i}=\left\{\operatorname{Inf}_{i}, O \operatorname{Opl}_{i}, \operatorname{Gol}_{i}, \operatorname{Sil}_{i}, \operatorname{Dji}_{i}, \operatorname{Din}_{i}\right\}
$$

By using this definition, the proposed FSA is as follows:

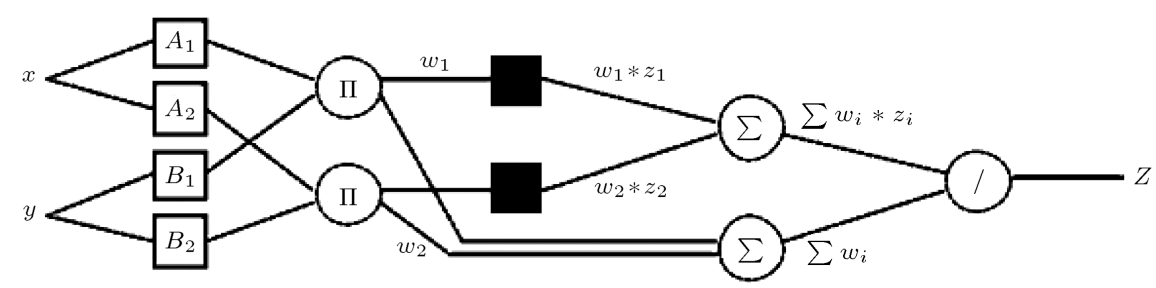

Figure 1. Two-input single-output architecture of Adaptive Neuro-Fuzzy Inference System (ANFIS) [32-35]. 
Table 1. A set of parameters under consideration in Algorithm 1.

\begin{tabular}{|c|c|c|}
\hline Application & Target & $E V_{i}$ \\
\hline Oil price & $O p_{i}$ & Infi, Int $t_{i} O p l_{i}, G p_{i}, S_{i l}, D_{j i} i_{i}, \operatorname{Din}_{i}$ \\
\hline Gold price & $G p_{i}$ & Infi, Int ${ }_{i} O p l_{i}, O p_{i}, S_{i} l_{i}, D j i_{i}, D_{i n}$ \\
\hline Oil demand function & $O d_{i}$ & Inf $_{i}$, Int $_{i} O \mathrm{Opl}_{i}, G p_{i}, \mathrm{Sil}_{i}, \mathrm{Dj}_{i}, \mathrm{Din}_{i}, O \mathrm{p}_{i}$ \\
\hline Gold demand function & $G d_{i}$ & Inf $_{i}$, Int $_{i} O p l_{i}, G p_{i}, S_{i l_{i}}, D j i_{i}, \operatorname{Din}_{i}, O p_{i}$ \\
\hline
\end{tabular}

Table 2. Economic variables under consideration $[38,39]$.

\begin{tabular}{ccccc}
\hline & Input variable & Unit & Symbol & Source \\
\hline 1 & US inflation rate & - & Inf & http://inflationdata.com \\
2 & Interest rate & - & Int & http://www.EconStats.com \\
3 & OPEC oil production level & Thousand barrels per day & Opl & http://tonto.eia.gov \\
4 & Gold price & $\$ /$ ounce & $G p$ & http://www.gold.org \\
5 & Silver price & $\$ /$ ounce & Sil & https://www.silverinstitute.org \\
6 & Market index & $\$$ & $D j i$ & http://finance.yahoo.com \\
7 & U.S. dollar index & - & Din & http://research.stlouisfed.org \\
8 & Oil price (USA F.O.B. cost of OPEC) & Dollars per barrel & Op & http://tonto.eia.gov \\
9 & U.S. crude oil imports from OPEC & Thousand barrels & Od & http://tonto.eia.gov \\
10 & Global gold demand & Tones & $G d$ & http://www.gold.org \\
\hline
\end{tabular}

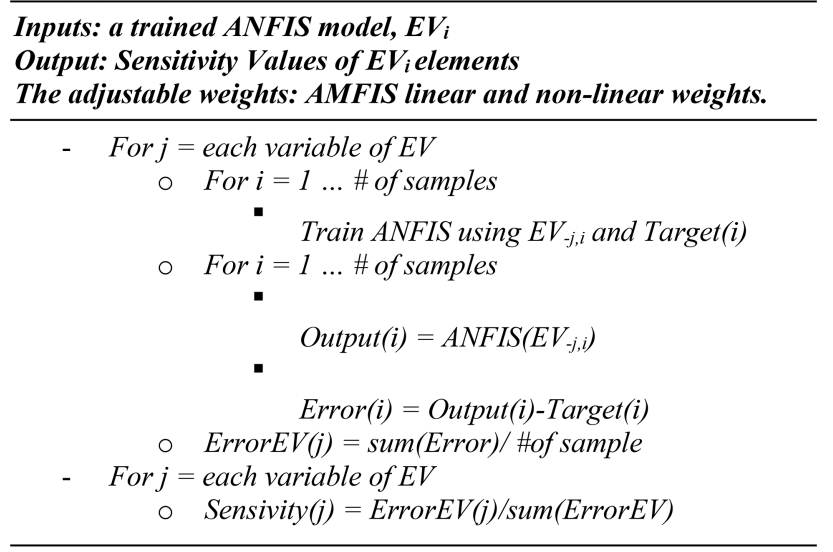

Algorithm 1. Fuzzy sensitivity analyzer.

In the algorithm, function $\operatorname{sum}(x)$ returns the sum of values of the array $x$. In Algorithm 1, $E V_{i}$ should be defined for every economic time series. Table 1 shows them, and Table 2 provides more information about these economic variables. Thus, the inputs and outputs of ANFIS for training in Algorithm 1 must be considered, as presented in Table 1. For example, for demand SA, the inputs include Inf, Int, Opl, Gol, Sil, Dji, Din, and $O p$ in the $i$ th period and the output of the model is $O d$ (U.S. crude oil imports from OPEC) and $G d$ (Global gold demand).

\section{Numerical results}

Oil and gold markets play critical roles in other large commodity markets, and their SA is very important
[39-44]. In this section, oil and gold time series is used to assess the proposed FSA. According to Algorithm 1, the result of the FSA is dependent on the prediction results of ANFIS model in the time series. The prediction results of ANFIS for price and demand functions of gold and oil are presented in Figures 3-6, and the final result of FSA is presented in Figure 7. The prediction results are compared with an optimum ANN in Tables 3 and 4. According to the comparative results, ANFIS can make more accurate predictions. In this experiment, the inputs and outputs of ANFIS are determined, as shown in Table 1. For example, in the case of oil/gold demand prediction, inputs include Inf, Int, Opl, Gol, Sil, Dji, Din, and $O p$ in the $i$ th period, and the outputs of the model are $O d$ (U.S. crude oil imports from OPEC) and $G d$ (Global gold demand). Moreover, two or more previous values of the outputs can be considered as input variables. In Table 2, for oil demand learning, monthly datasets were downloaded from http://tonto.eia.gov. In addition, for gold demand learning, the quarterly datasets were obtained from a source presented in Table 2. Figure 3 shows the curves of estimated values of oil demand versus monthly observations from 2002 till 2012 and in the steady state. A correlation COR $=0.22298$ is obtained by the ANFIS model. Additionally, results show that RMSE $=181.9693 \pm 0$ obtained by ANFIS simulation is lower than $236.6038+113.0307$, obtained by ANN. Tables 3 and 4 summarize the comparative results.

The gold demand prediction results are shown in 

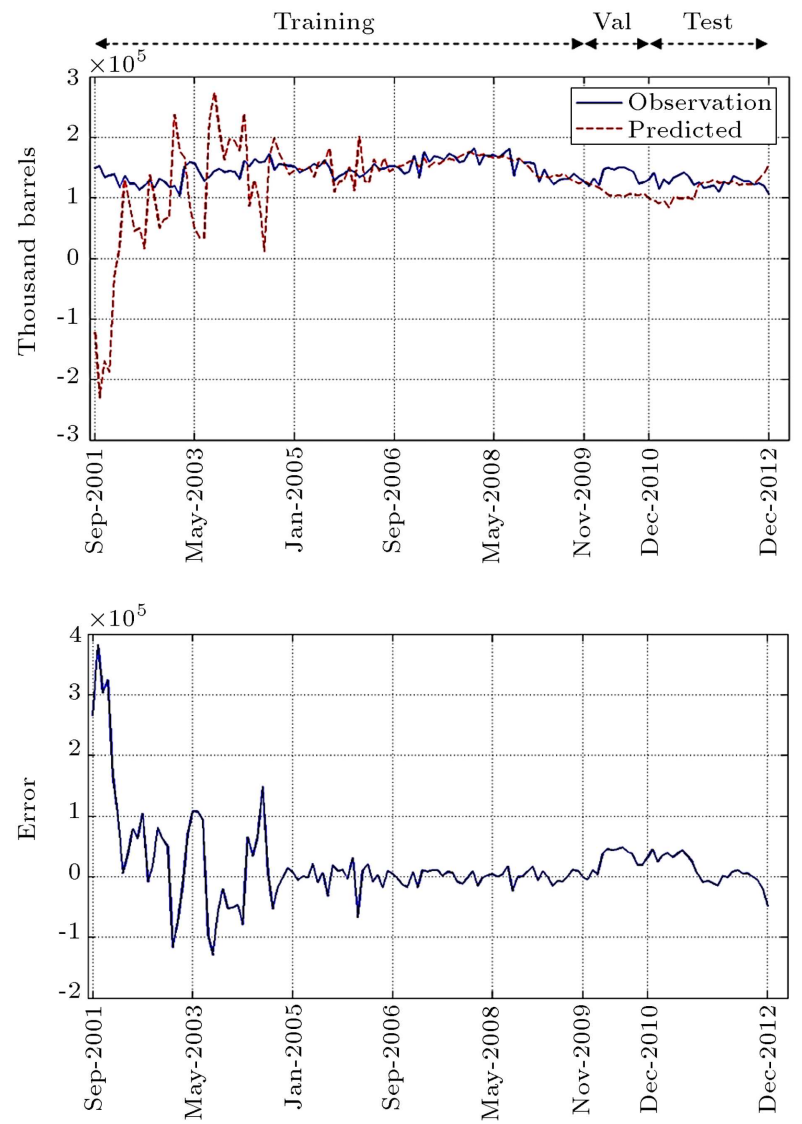

Figure 3. Online predicted oil demand values (top) and related error (bottom) from the start point in Sep. 2001 obtained using Adaptive Neuro-Fuzzy Inference System (ANFIS).

Figures 4 and 5 . Figure 4 shows the observed and predicted demand and related error between the 4th quarter of 2001 and the 4th quarter of 2012. The COR $=0.78801$ is obtained by the ANFIS-based model in the steady state. In subtractive clustering, radii $=[0.5$

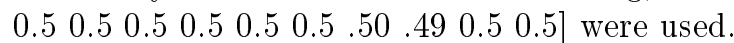

Figure 6 shows the target and predicted gold prices and the related error obtained from the proposed input variables, presented in Table 2. Figure 6 presents the results of the prediction from the start point in Dec2001. As illustrated in Figure 6, the last 24 months are used for testing the system. The predicted curve illustrated in Figure 6 is divided into three segments: The first is the training region between months [Sep2001 Nov-2009]; the second is the validating region between months (Nov-2009 Dec-2010), and the third is the testing region where the prediction results are validated between [Dec-2010 Dec-2012]. Figure 6 shows the curve of predicted prices of gold versus the observation from Sep-2001 till Dec-2012. As illustrated in Table 2, in gold prediction, the best COR $=0.97211$ is obtained by the model. According to the more experiments, if ANFIS does not apply the previous values of time series, then the error increases while the
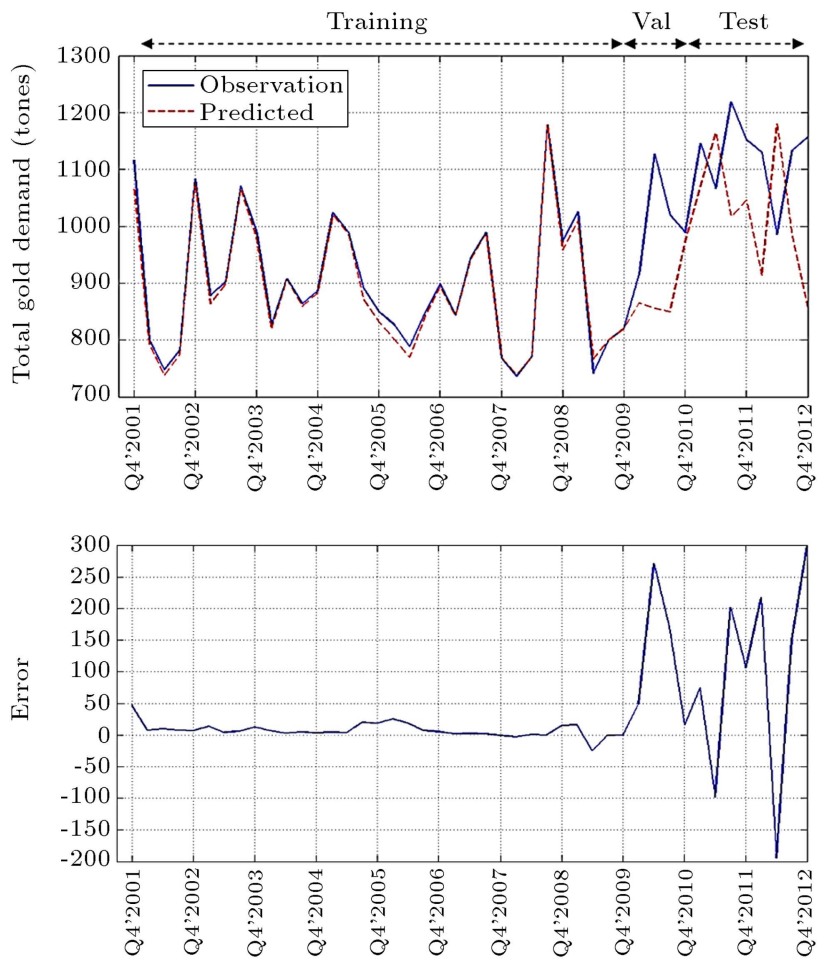

Figure 4. Online predicted gold demand values (top) and related error (bottom) from the start point in Sep. 2001 (Q4' 2001) obtained using Adaptive Neuro-Fuzzy Inference System (ANFIS).

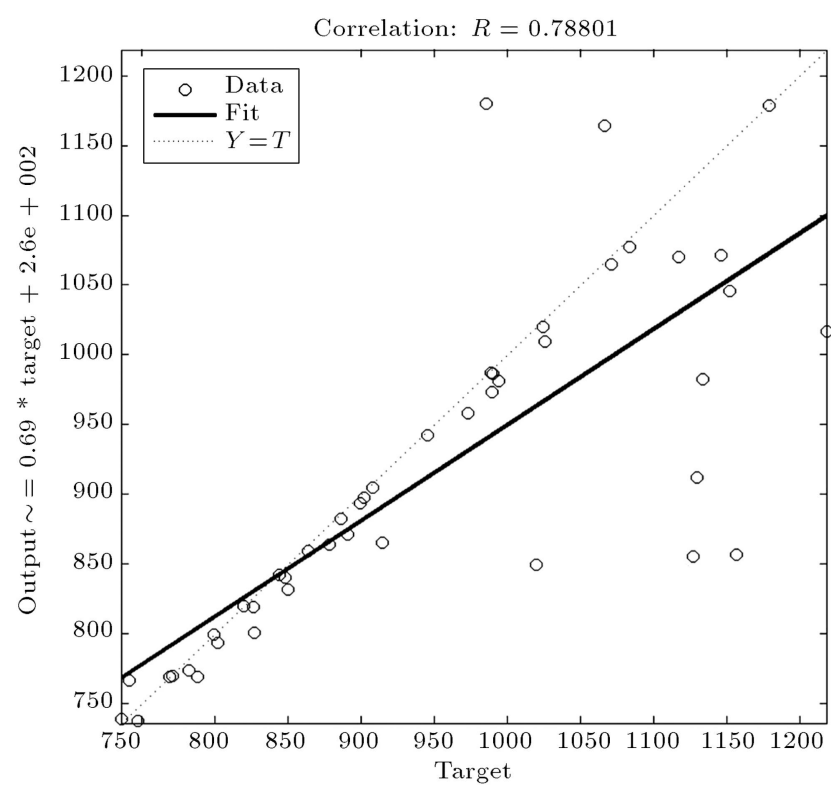

Figure 5. Actual versus desired outputs of gold demand between $Q^{\prime} 42001$ and $Q^{\prime} 42012$ obtained by the Adaptive Neuro-Fuzzy Inference System (ANFIS) model.

proposed input sets provide error $=255.4686 \pm 0$ in gold forecasting that is much lower than $354.5491 \pm 95.17189$ obtained by the optimum ANN. According to the Student-t test, these results are statistically significant. To assess the proposed FSA, the trained ANFIS 
Table 3. The average error, RMSE, and correlation comparisons between optimum Artificial Neural Network (ANN) and demand function estimation.

\begin{tabular}{ccccc}
\hline Time series & Model & RMSE & RMSE & Correlation \\
\hline \multirow{2}{*}{ Oil demand } & ANFIS & $34614 \pm 0$ & $23757 \pm 0$ & 0.22298 \\
& Optimum ANN & $31082.11 \pm 1860.656$ & $23982.22 \pm 8781.989$ & 0.20403 \\
\multirow{2}{*}{ Gold demand } & ANFIS & $13.4329 \pm 0$ & $181.9693 \pm 0$ & 0.78801 \\
& Optimum ANN & $146.81 \pm 44.54263$ & $236.6038 \pm 113.0307$ & 0.32314 \\
\hline
\end{tabular}

Table 4. Comparative results of price prediction between Artificial Neural Network (ANN) and Adaptive Neuro-Fuzzy Inference System (ANFIS) and the proposed variables set.

\begin{tabular}{ccccc}
\hline Time series & Model & Training set RMSE & Test set RMSE & Best correlation \\
\hline \multirow{2}{*}{ Gold } & ANFIS & $131.7283 \pm 0$ & $255.4686 \pm 0$ & 0.97211 \\
& Optimum ANN & $205.4037 \pm 229.2613$ & $354.5491 \pm 95.17189$ & 0.96091 \\
\hline
\end{tabular}
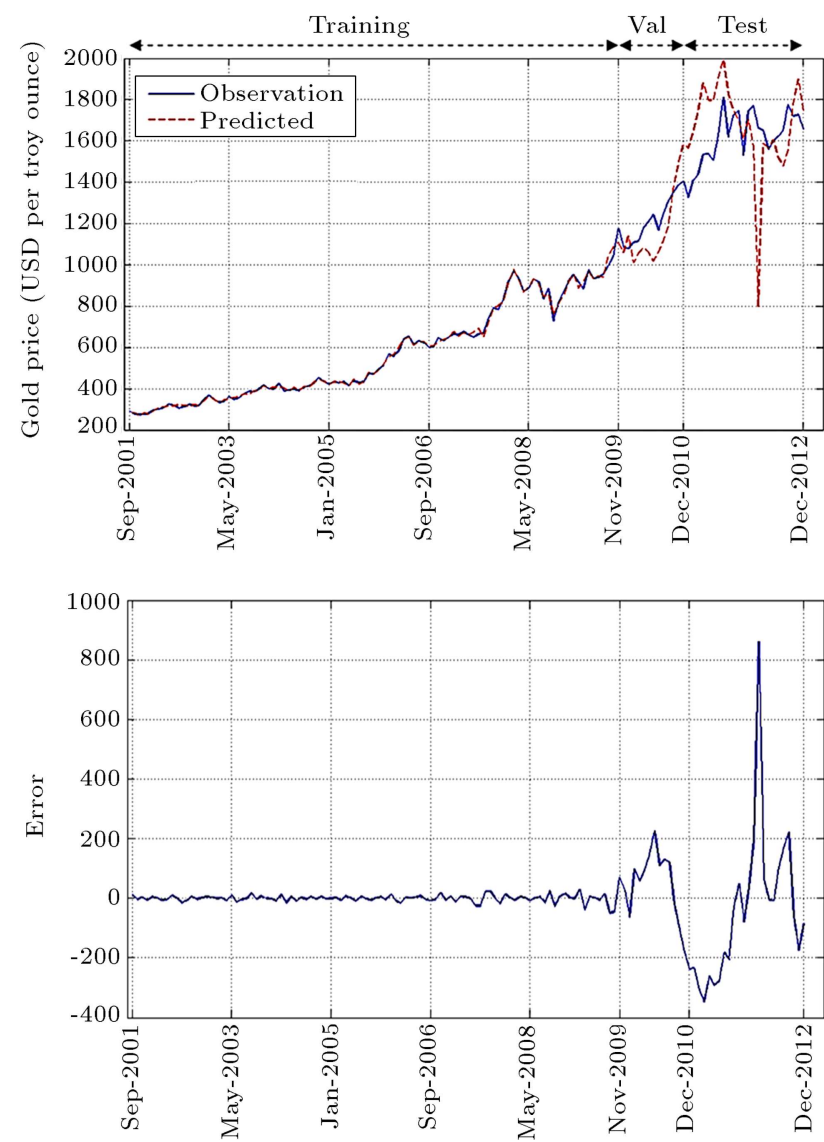

Figure 6. Predicted gold prices (top) and related error (bottom) from the start point in Sep. 2001 obtained using Adaptive Neuro-Fuzzy Inference System (ANFIS).

model with the parameters provided in Table 1 is applied in Algorithm 1. Figure 7 shows the final results of SA. The sensitivity value of a variable shows the relationship between the variable and output. For example, in oil price predictions, If the oil price has no relation with a variable like $x$, then the sensitivity $(x)$
$=0$, i.e., $x$, does not affect directly the oil price, or it is not independent and highly correlated with another input variable. The largest value of sensitivity shows that the variable is the most sensitive factor affecting oil prices.

The importance of parameters on the oil price, oil demand, gold price, and gold demand is shown in Figure 7. According to Figure 7, the most effective parameters for the oil price include inflation rate and market index. Figure 7 presents the sensitivity average and the confidence interval obtained by the proposed FSA with various learning parameters such as the number of rules in ANFIS. It is obvious that, according to the confidence interval, the results of market index and inflation rate are statistically significant. The results indicated in Figure 7 are based on students' t-test with $95 \%$ confidence. Figure 7 shows that the sensitivity average values of 0.21 and 0.20 are obtained by FSA for inflation rate and dollar index, respectively. Furthermore, the highest sensitivity is obtained for inflation rate and dollar index in oil demand modeling. These results are statistically significant with respect to the OPEC oil production level, interest rate, and silver price; however, they are not statistically significant with respect to the gold price and oil price. Gold price model is highly dependent upon the silver price. Therefore, the proposed model verifies the results reported by Yazdani-Chamzini et al. (2012) [9] about gold and silver dependency.

\section{Conclusion}

The FSA was proposed here to analyze the sensitivity of economic parameters (source code may be accessible from www.bitools.ir). The proposed FSA applied an ANFIS model in order to predict the economic time series. It was shown that ANFIS was an appropriate model for senility analysis of price and demand. 

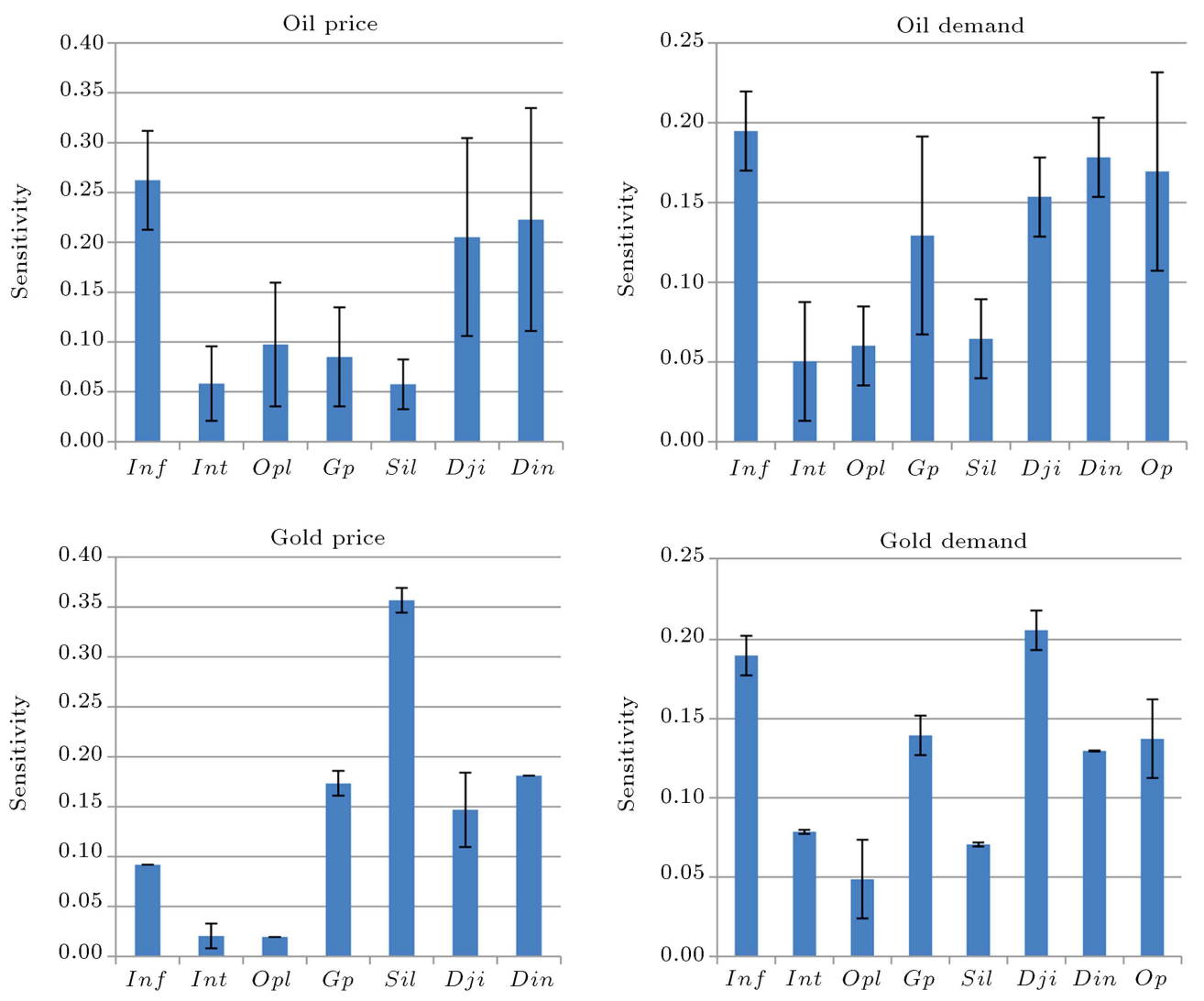

Figure 7. Sensitivity analysis of economic variables obtained by the proposed Fuzzy Sensitivity Analyzer (FSA).

Furthermore, numerical studies presented the following conclusions. Firstly, according to the results of fuzzy $\mathrm{SA}$, the importance of the inflation rate was higher than OPEC oil production level, market index, USD index, gold price, interest rate, silver price in one month ahead of the prediction of oil price and demand. The proposed FSA indicates that oil price is highly dependent upon the inflation rate, dollar index, and market index, while OPEC production level and gold price have less impact. Secondly, in the gold price modeling, the highest sensitivity was obtained from silver price while demand for gold was a function of market index and inflation rate. Demand for gold was a function of market index and inflation rate. Some results obtained here are new, and some others confirm the results of previous studies, especially the dependency of gold and silver price. These results showed that the proposed learning-based method was highly reliable for testing on other applications. FSA showed a high performance in price and demand modeling and could be used in various applications such as sensitivity analysis of environmental models, MADM, renewable energy analysis, etc. Additionally, the excellent results of ANFIS in SA showed that it could be a proper model for similarity analysis methods [17,45-47] such as those for economic data.

However, the proposed FSA is susceptible to some weaknesses. It cannot directly measure the interactions between the parameters. These interactions are very important and can lead to globally applicable SA results. For future developments, factorial design [4] and interactions of parameters with each other should be considered. The factorial design enables the measurement of interactions between each different group of factors [4], and these interactions are very important and may affect the SA results.

\section{Acknowledgement}

The authors would like to thank the reviewers for their feedback on the paper.

\section{References}

1. Kilian, L., and Vigfusson, R.J. "Do oil prices help forecast US real GDP? The role of nonlinearities and asymmetries", Journal of Business \& Economic Statistics, 31(1), pp. 78-93 (2013).

2. Iooss, B. and Lemaître, P. "A review on global sensitivity analysis methods", In Uncertainty Management in Simulation-Optimization of Complex Systems, pp. 101-122 (2015).

3. Sarrazin, F., Pianosi, F., and Wagener, T. "Global sensitivity analysis of environmental models: convergence 
and validation", Environmental Modelling \& Software, 79, pp. 135-152 (2016).

4. Kamiński, B., Jakubczyk, M., and Szufel, P. "A framework for sensitivity analysis of decision trees", Central European Journal of Operations Research, 26(1), pp. 135-159 (2018).

5. Escalante Soberanis, M.A., Mithrush, T., Bassam, A., et al. "A sensitivity analysis to determine technical and economic feasibility of energy storage systems implementation: A flow battery case study", Renewable Energy, 115, pp. 547-557 (2018).

6. Borgonovo, E. and Plischke, E. "Sensitivity analysis: a review of recent advances", European Journal of Operational Research, 248(3), pp. 869-887 (2016).

7. Antucheviciene, J., Kala, Z., Marzouk, M., et al. "Solving civil engineering problems by means of fuzzy and stochastic MCDM methods: current state and future research", Mathematical Problems in Engineering (2015).

8. Kala, Z. and Vales, J. "Sensitivity assessment and lateral-torsional buckling design of I-beams using solid finite elements", Journal of Constructional Steel Research, 139, pp. 110-122 (2017).

9. Yazdani-Chamzini, A., Haji Yakhchali, S., Volungevičiene, D., et al. "Forecasting gold price changes by using adaptive network fuzzy inference system", Journal of Business Economics and Management, 13(5), pp. 994-1010 (2012).

10. Harenberg, D., Marelli, S., Sudret, B., and Winschel, V. "Uncertainty quantification and global sensitivity analysis for economic models", Quantitative Economics, 10(1), pp. 1-41 (2019).

11. Ghosh, N. and Hazra, S. "Sensitivity analysis with calibration of natural resource variables under climate change: comparing computable general equilibrium (CGE) and econometric frameworks", Natural Resources Management: Concepts, Methodologies, Tools, and Applications, IGI Global, pp. 681-691 (2017).

12. Ferretti, F., Saltelli, A., and Tarantola, S. "Trends in sensitivity analysis practice in the last decade", Science of the Total Environment, 568, pp. 666-670 (2016).

13. Rahmati, O., Tahmasebipour, N., Haghizadeh, A., et al. "Evaluating the influence of geo-environmental factors on gully erosion in a semi-arid region of Iran: An integrated framework", Science of the Total Environment, 579, pp. 913-927 (2017).

14. Kala, Z. and Valeš, J. "Global sensitivity analysis of lateral-torsional buckling resistance based on finite element simulations", Engineering Structures, 134, pp. 37-47 (2017).

15. Bams, D., Blanchard, G., Honarvar, I., et al. "Does oil and gold price uncertainty matter for the stock market?", Journal of Empirical Finance, 44, pp. 270285 (2017).
16. Valdivia, S., and Morales, A. "Determinants of the index of prices and quotations on the Mexican stock exchange: Sensitivity analysis based on artificial neural networks", Global Journal of Business Research, 10(2), pp. 27-32 (2016).

17. Keshavarz Ghorabaee, M., Amiri, M., Kazimieras Zavadskas, et al. "A new hybrid fuzzy MCDM approach for evaluation of construction equipment with sustainability considerations", Archives of Civil and Mechanical Engineering, 18(1), pp. 32-49 (2018).

18. Wang, L., Zhang, H., Wang, J., and Li, L. "Picture fuzzy normalized projection-based VIKOR method for the risk evaluation of construction project", Applied Soft Computing, 64, pp. 216-226 (2018).

19. Tigdemir, M., and Kalyoncuoglu, S.F. "Fatigue life prediction of the modified asphalt mixtures with ANFIS modeling", Scientia Iranica, Transactions A, Civil Engineering, 24(1), p. 72 (2017).

20. Hasheminejad, M.M., Sohankar, N., and Hajiannia, A. "Predicting the collapsibility potential of unsaturated soils using adaptive neural fuzzy inference system and particle swarm optimization", Scientia Iranica, 25(6), pp. 2980-2996 (2018).

21. Asvar, F., Shirmohammadi Faradonbeh, A., and Barkhordari, K. "Predicting potential of controlled blasting-induced liquefaction using neural networks and neuro-fuzzy system", Scientia Iranica, 25(2), pp. 617-631 (2018).

22. ÖZEL, C. and Topsakal, A. "Comparison of ANFIS and ANN for estimation of thermal conductivity coefficients of construction materials volume", 22(6), pp. 2001-2011 (2015).

23. Nazlioglu, S., Gormus, N.A., and Soytas, U. "Oil prices and real estate investment trusts (REITs): Gradualshift causality and volatility transmission analysis", Energy Economics, 60, pp. 168-175 (2016).

24. Silvennoinen, A. and Thorp, S. "Crude oil and agricultural futures: an analysis of correlation dynamics", Journal of Futures Markets, 36(6), pp. 522-544 (2016).

25. Jobling, A. and Jamasb, T. "Price volatility and demand for oil: A comparative analysis of developed and developing countries", Economic Analysis and Policy, 53, pp. 96-113 (2017).

26. Liu, Z., Johnson, T.G., and Altman, I. "The moderating role of biomass availability in biopower co-firing-A sensitivity analysis", Journal of Cleaner Production, 135, pp. 523-532 (2016).

27. Tse, K.-K., Chow, T.-T., and Su, Y. "Performance evaluation and economic analysis of a full scale waterbased photovoltaic/thermal (PV/T) system in an office building", Energy and Buildings, 122, pp. 42-52 (2016).

28. Chang, A.Y., Robinson, L.A., Hammitt, J.K., et al. "Economics in "Global Health 2035": a sensitivity analysis of the value of a life year estimates", Journal of Global Health, 7(1), pp. 1-13 (2017). 
29. Liu, H. "Cost estimation and sensitivity analysis on cost factors: a case study on Taylor Kriging, regression and artificial neural networks", The Engineering Economist, 55(3), pp. 201-224 (2010).

30. Thawornwong, S., Enke, D., and Dagli, C. "Neural networks as a decision maker for stock trading: a technical analysis approach", International Journal of Smart Engineering System Design, 5(4), pp. 313-325 (2003).

31. Ince, H. and Trafalis, T.B. "Short term forecasting with support vector machines and application to stock price prediction", International Journal of General Systems, 37(6), pp. 677-687 (2008).

32. Ince, H. and Trafalis, T.B. "Kernel principal component analysis and support vector machines for stock price prediction", Iie Transactions, 39(6), pp. 629-637 (2007).

33. Jang, J.-S.R. "ANFIS: adaptive-network-based fuzzy inference system", IEEE Transactions on Systems, Man, and Cybernetics, 23(3), pp. 665-685 (1993).

34. Jang, J.-S.R., Sun, C.T., and Mizutani, E. "Neurofuzzy and soft computing-a computational approach to learning and machine intelligence [Book Review]", IEEE Transactions on Automatic Control, 42(10), pp. 1482-1484 (1997).

35. Chiu, S.L. "Fuzzy model identification based on cluster estimation", Journal of Intelligent \& Fuzzy Systems, 2(3), pp. 267-278 (1994).

36. Yager, R.R. and Filev, D.P. "Generation of fuzzy rules by mountain clustering", Journal of Intelligent \& Fuzzy Systems, 2(3), pp. 209-219 (1994).

37. Lotfi, E. and Karimi, M.R. "OPEC oil price prediction using ANFIS", Journal of Mathematics and Computer Science, 10, pp. 286-296 (2014).

38. Lotfi, E., Darini, M., and Karimi-T, M.R. "Cost estimation using ANFIS", The Engineering Economist, 61(2), pp. 144-154 (2016).

39. Lotfi, E. and Karimi, M.R. "An economic dataset for OPEC oil economic functions", Majlesi Journal of Energy Management, 3(3), pp. 1-8 (2014).

40. Narayan, P.k., Narayan, S., and Zheng, X. "Gold and oil futures markets: Are ma..rkets efficient?", Applied Energy, 87(10), pp. 3299-3303 (2010).

41. Melvin, M. and Sultan, J. "South African political unrest, oil prices, and the time varying risk premium in the gold futures market", The Journal of Futures Market, 10(2), pp. 103-111 (1990).

42. Zhang, Y.-J. and Wei, Y.-M. "The crude oil market and the gold market: Evidence for cointegration, causality and price discovery", Resources Policy, 35(3), pp. 168-177 (2010).

43. Sujit, K.S. and Rajesh Kumar, B. "Study on dynamic relationship among gold price, oil price, exchange rate and stock market returns", International Journal of
Applied Business and Economic Research, 9(2), pp. 145-165 (2011).

44. Smith, A.E. and Mason, A.K. "Cost estimation predictive modeling: Regression versus neural network", The Engineering Economist, 42(2), pp. 137-161 (1997).

45. Ghermandi, A., Sheela, A.M., and Justus, J. "Integrating similarity anlaysis and ecosystem service value transfer: Results from a tropical coastal wetland in India", Ecosystem Services, 22, pp. 73-82 (2016).

46. Kubo, M., Sato, H., Yamaguchi, A., and Aruka, Y. "Similarity analysis of survey on employment trends in Japan", In Intelligent and Evolutionary Systems, pp. 211-221, Springer, Cham (2017).

47. Ciampi, G., Rosato, A., and Sibilio, S. "Thermoeconomic sensitivity analysis by dynamic simulations of a small Italian solar district heating system with a seasonal borehole thermal energy storage", Energy, 143, pp. 757-771 (2018).

\section{Biographies}

Ehsan Lotfi is a faculty member of the Department of Computer Engineering, Azad University, Torbat-eJam Branch, Torbat-e-Jam, Iran. He received the BSc degree in Computer Engineering (2006) from Ferdowsi University of Mashhad, MSc degree in Artificial Intelligence (2009) from Azad University, Mashhad Branch, and his $\mathrm{PhD}$ in Artificial Intelligence from Science and Research Campus of Azad University. From 2006 to 2008, he was a Research Assistant in Khorasan Research Center for Advanced Technology of Iran. His research interest includes cognitive sciences, computational and artificial intelligence, soft computing, and their applications. He has published 12 peer-reviewed articles and a national patent in his research programs.

Saeedeh Babrzadeh received the BS (2013) in IT Engineering from Elmi Karbordi University of Shiraz, Iran and MS degree (2016) from Payam-e Noor University of Asalooyeh, Iran. Her research interest includes target tracking, E-commerce, and multimedia system.

Abbas Khosravi is an Associate Professor of Systems Modelling and Soft Computing at the Department of Inst Intelligent Sys Res \& Inn, Deakin University, Australia. From 2010 to the present time, he has been a research fellow in Centre for Intelligent Systems Research, Deakin University, Australia. He received his PhD from Deakin University in 2010. His research interests include neural networks-fuzzy logic systems, computational intelligence, evolutionary optimization, uncertainty quantification, and application of AI-based methods for decision-making. 